\title{
Genetic Organization and Evolution of Electromechanical Objects with Adaptive Geometry of Active Zone
}

\author{
Vasyl Shynkarenko ${ }^{1}$, Ali Makki ${ }^{2}$, Viktoriia Kotliarova ${ }^{1, *}$, Anna Shymanska ${ }^{1}$, Pavlo Krasovskyi ${ }^{1}$ \\ ${ }^{1}$ Department of Electromechanics, National Technical University of Ukraine "Igor Sikorsky Kyiv Polytechnic Institute”, Kyiv, 03056, \\ Ukraine
}

${ }^{2}$ KEEP'MOTION Company, Luzinay, 38200, France

\begin{tabular}{l} 
A R T I C L E I N F O \\
\hline Article history: \\
Received: 12 August, 2020 \\
Accepted: 01 September, 2020 \\
Online: 24 September, 2020
\end{tabular}

Keywords:

Electromechanical object

Active zone

Variable geometry

Electromagnetic chromosome

Genetic code

Macrogenetic program

Synthesis

"Elastic" electromechanics

Functional evolution

\begin{abstract}
A B S T R A C T
The paper is devoted to the presentation of a new methodological approach (new philosophy) to the formulation and solution of directed search and synthesis of electromechanical objects for a given function problems. The object under the study is a class of electrical machines and electromechanical devices which operation is carried out with a variable structure or geometry of the active zone. The research is relevant due to the characteristic trend in the evolution of modern technology which is associated with the creation of complex technical systems with the ability to change the structure and spatial geometry of the executive body in accordance with changing of external factors. The novelty of the synthesis methodology is determined by genetic nature of the technical evolution of electromechanical objects and by genetic programs of structure formation using. According to the results of research the genetic principles and macrogenetic programs of electromechanical objects with variable spatial geometry of active parts have been determined for the very first time. The area of existence and results of genetic synthesis of "elastic" electromechanics objects are presented. The reliability of genetic models, genetic programs and the results of the electromechanical objects with adaptive spatial geometry of the active zone synthesis is confirmed by the results of evolutionary experiments.
\end{abstract}

\section{Introduction}

One of the current trends in the development of mobile technical systems is associated with the transition from classical rigid forms and monostructures to spatially distributed structures with adaptive spatial geometry which functioning is as close as possible to natural analogues. This trend is relevant due to the growing demands of improving the dynamic characteristics and mass and size dimensions, increasing energy efficiency and reliability of technical systems based on the use of the latest materials and the widespread introduction of digital technologies. In the process of interaction between the object and external environment, the energy characteristics of the whole system change which is accompanied by a changing of the parameters and physical state of its elements. Factors of external influence often determine the necessity of the spatial geometry and structure of the system adaptation in the area of their direct interaction. Spatially adaptive systems and technologies are already used in modern aviation, space and military technics, electronics, automotive,

*Corresponding Author: Viktoriia Kotliarova, sharik_2004@ukr.net

www.astesj.com

https://dx.doi.org/10.25046/aj050564 robotics, machine-building and other science-intensive technical fields [1]-[5]. The latest direction of technology development has not yet received an unambiguous definition and occurs under various terminological names: "elastic mechanics", "machines with adaptive morphology", "soft robotics", "flexible electronics", "reconfigured systems", "objects-transformers", etc.

Analysis of the functional and technical evolution of electromechanical converters of energy (EMCE) shows a great variety of electrical machines and electromechanical devices, which operation of which is directly related to changes in the structure and geometry of their active zone in space and time. In the concept of structural-system approach, these electromechanical objects (EM-objects) and devices belong to the class of genetically organized systems (GOS) which structural diversity is determined by the relevant genetic programs and their development is regulated by systemic laws of genetic evolution [6].

The object of research is the functional classes of modular EMCE which operating routines are realized with a change in the spatial geometry and structure of the active parts. An 
informational sources review shows the absence of a systematic analysis of the structural organization and technical evolution of these objects and is currently limited to describing only their known technical implementations. The tasks of determination the principles of structure formation of EM-objects with variable geometry of the active zone and their genetic programs and of analysis the directions of their structural and functional evolution.

\section{Genetic Organization of Electromagnetic Systems}

The genetic approach in modern science acquires a key role in understanding of the fundamental principles of structural organization and laws of complex systems developing which opens the possibility of implementing scenarios for predicting and managing heredity in the generalized language of genetic information not only in biological systems but also in systems of anthropogenic origin [7], [8]. General system principles of hierarchical structural organization of complex systems, interdisciplinary structural isomorphisms and homologies indicate that the class of GOS includes not only systems of natural origin (biological, chemical, crystallographic) but also technical, musical, linguistic, mathematical and other anthropogenic systems. Evolutionary alive and anthropogenic systems regardless of their level of complexity have two alternative properties: heredity and variability. Heredity is manifested in the fact that an arbitrary object, population or species as a whole, retain in a number of generations their inherent genetic characteristic and properties. The property of variability predetermines a variety of options for the implementation and ways of development of hereditary structures by adapting them to changing environmental conditions.
The theoretical basis of GOS are interconnected system principles of structural organization and information heredity which predetermine the diversity and development of systems of different physical nature. The principles of structure formation and the genetically acceptable diversity of GOS objects are determined through the genetic information of the elemental basis, which is ordered by genetic classifications (GC) of the natural type. Periodic genetic classifications in the concept of GOS perform the function of generative systems. The category of generating systems includes the periodic classification of chemical elements, the classification of 230 groups of crystals symmetry, the classification of geographical zoning, the periodic classification of natural numbers and others. Genetic organization and evolution are determined by a system of interrelated principles and laws, the form of presentation of which is the generative system - the Periodic Genetic Classification (Table 1). The absence of certain invariant principles in GOS of a certain physical nature should be considered as a temporary phenomenon which is explained by the unevenness of structural and systemic studies or the lack of genetic classifications (generative systems) of the corresponding elemental basis. The biological science is particularly at the level where the theoretical basis operates on almost all system-wide principles of genetic evolution except its own generative periodic table the search for which is continued today [9].

As for the electromechanics principles are shown in Table 1 were absent in the classical theory of electric machines, and became known only after the discovery and analysis of the invariant properties of GC (Figure 1). Analysis of intersystem isomorphisms, after some time, revealed the principles of invariance of GOS also in the system of natural numbers [10].

Table 1: System-wide Principles of Invariance in Genetically Organized Systems of Different Physical Nature (Fragment)

\begin{tabular}{|l|c|c|c|c|c|c|}
\hline \multicolumn{1}{|c|}{ Invariants of GOS } & Biology & Music & Linguistics & Chemistry & $\begin{array}{c}\text { Electro- } \\
\text { mechanics }\end{array}$ & $\begin{array}{c}\text { Natural } \\
\text { numbers }\end{array}$ \\
\hline Own elements base & + & + & + & + & + \\
\hline $\begin{array}{l}\text { Generative periodic } \\
\text { system of elements }\end{array}$ & $?$ & + & $?$ & + & + & + \\
\hline $\begin{array}{l}\text { Universal genetic code } \\
\text { The principle of symmetry } \\
\text { saving }\end{array}$ & + & + & + & + & + & + \\
\hline $\begin{array}{l}\text { The principle of } \\
\text { topological invariance }\end{array}$ & + & + & + & + & + \\
\hline $\begin{array}{l}\text { The principle of genetic } \\
\text { information saving }\end{array}$ & + & + & + & + & + \\
\hline Structures genetic memory & + & + & + & + & + \\
\hline The principle of parity & + & + & + & + & + \\
\hline
\end{tabular}

+ discovered or have been investigated;

? currently missing or need to be clarificated. 
Electromagnetic field is a fundamental physical property of material and natural phenomena. The magnetic field was formed in the early stages of the evolution of the universe and is primary comparatively with chemical and biological evolution.

The information which accompanies magnetic fields has exceptional importance for studying the evolution of different physical nature systems. The discovery of the Genetic Classification of primary sources of the electromagnetic field have established that EMCE as systems of both natural and anthropogenic origin belong to the category of genetically organized systems [6]. The elemental basis of the GC is represented by the primary sources of the electromagnetic field (electromagnetic chromosomes) which perform the role of the original elementary structures in the tasks of combinatorial and topological synthesis of structures in arbitrary level of complexity. The position and invariant properties of an arbitrary primary source of field in the structure of the GC are determined by its genetic information which is represented by a universal genetic code. Electromagnetic, topological and geometric properties of the primary structures of the GC are determined by the systemwide principles of electric charge, symmetry and topology stability.

Elemental and information basis of the first large period of GC is represented by 36 oriented field sources (electromagnetic chromosomes) of the basic level, the location and genetic information of which unambiguously determine their belonging to the corresponding geometric class of active surfaces (Genus taxonomic category), their connectivity and orientation (Homological series), genetic code (Species category) and the principle of parity (Twin-species category). There is a deterministic connection between the elemental basis of GC and EM-objects-descendants which is determined by the principles of genetic structure and information stability. Therefore, an arbitrary EM-object is a carrier of genetic information which recognizes its location in the subject area of the generative system as well as determines the taxonomic status and the corresponding genetic programs of structure and its relationship with other elements of the system.

The structure of the GC is a form of presenting the fundamental principles the structure and information stability as well as the integral periodic law.

According to the results of genetic analysis and numerous evolutionary experiments it is established that the structural diversity and properties of electromagnetic and electromechanical objects were created by many generations of specialists are endowed with highly ordered system connections recognized by universal genetic codes of elemental GC basis.

The set of these provisions is a system basis for setting and solving fundamentally new problems including problems of determining and decoding of genetic programs of arbitrary functional classes of electromechanical systems (EM-systems), implementation of structural prediction and genetic synthesis technologies, development of genetic data banks and knowledge bases.

\section{Spatial Geometry and Topology of Electromagnetic Structure}

Spatial geometry and topology in the evolution of structures are fundamental problems in the theory of genetically organized systems of arbitrary physical nature. "The problem of the inheritance of forms is one of the most important problems of the human mind. Any form, any state of a certain process is a product of the union or intersection of elementary forms (atoms) that have similarity, indivisibility and immutability... Any evolution comes down to changes in the relative position, organization of these elementary forms" [11]. "...In modern physics it is assumption that the set of elementary forms and functions of matter is limited, and new forms and functions appear only as a result of combinations and transformations of basic forms and functions" [12]. These provisions are necessary conditions for the development of GOS.

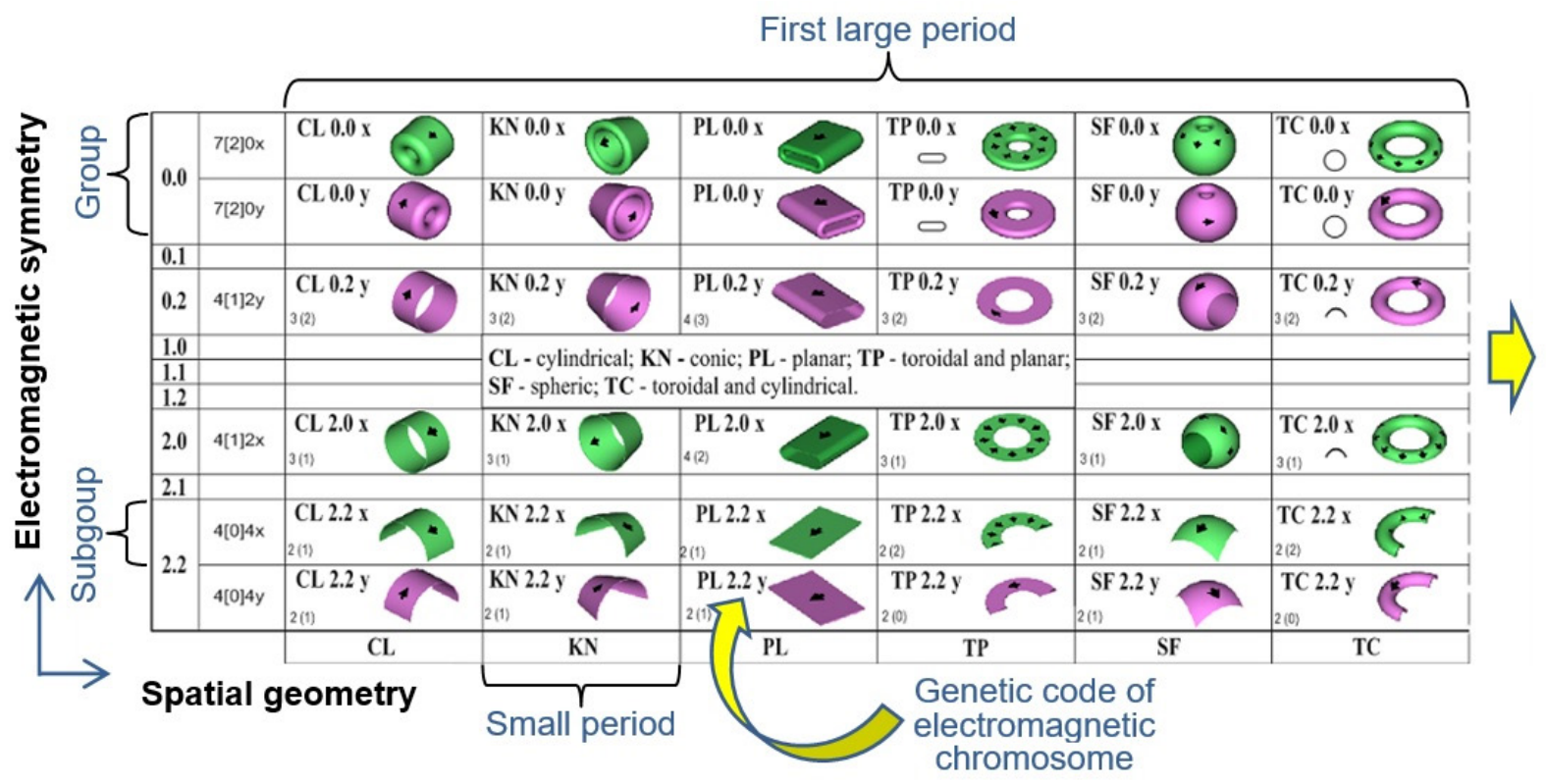

Figure 1: Generative System - Genetic Classification of Primary Sources of Electromagnetic Field (the First Large Period) 
Spatial geometry, electromagnetic symmetry and topology of primary sources of electromagnetic field (electromagnetic chromosomes) define the concept of genetic information and play the role of invariants in the structure of arbitrary Species of EMCE. In the structure of the universal genetic code, spatial geometry is encoded by the first component of genetic information which determines the Genus affiliation of objects-descendants. The structural equivalent of the spatial geometry of the primary field source is the active surface of the corresponding EM-object. The geometry of the active zone, electromagnetic symmetry and topological properties of the electromagnetic structure determine the principles of structure formation of EM-objects at all levels of their structural organization, starting from the level of electromagnetic chromosomes and ending with complex systems created in the process of evolution (Figure 2).

Changing of the spatial geometry and parameters of the secondary environment is a necessary condition for the functioning of the vast majority of EMCEs designed for direct implementation of technologies (magnetic and electrodynamic separators, electromechanical disintegrators, magnetohydrodynamic converters, etc.). So their analysis is a separate task. In this study structures with only variable spatial orientation and geometry of the primary active part (stator, armature, inductor, poles, etc.) are analyzed.

\section{Macrogenetic Programs}

The limits of arbitrary functional classes of EMCE existence and the quantitative composition of genetically acceptable Species are determined by their macrogenetic programs [13]. Macrogenetic programs are carriers of systematized information on the Species diversity of structures, including structural representatives of known Species and Species that are not involved yet in the technical evolution of the functional class. The problem of determining the genetic program will be considered on the example of a class of EM-objects the which functioning is carried out with a variable spatial orientation (OZ-rotation) of the active parts (Figure 3).

The integrated search function $F_{O Z}$ is determined by a set of the following partial requirements:

- the presence of a solid secondary part $\left(C_{2}\right)$;

- the possibility of OZ-rotation $(\beta=0 \div \pi)$ of the primary part relatively to the $O Z$-normal;

- invariability of the air gap ( $\delta \approx$ const $)$;

- ensuring the maximum area of overlap of the active zone $\left(S_{a}=\max \right)$.

Then the vector of the integral function $F_{O Z}$ in the multidimensional search space $R^{n}$ takes the following form:

$$
F_{O Z}=\left\{C_{2},(\beta=0 \div \pi),(\delta \approx \text { const }),\left(S_{a}=\max \right)\right\} \subset R^{n} .
$$

The search space is limited by the elemental basis of the first large period of GC (excluding sources-isotopes). This set of requirements is met by electromagnetic chromosomes of three Genuses: Spherical (SF), Flat (PL) and Toroidal Flat (TP) primary sources of the electromagnetic field. The results of genetic analysis show that the electromagnetic chromosomes of the Spherical and the Flat Genuses are endowed with the greatest tendency to rotational symmetry of the $O Z$-type

$$
Q_{S F}=(S F 0.0 y ; S F 0.0 x ; S F 0.2 y ; S F 2.0 x ; S F 2.2 y ; S F 2.2 x) \text {; }
$$

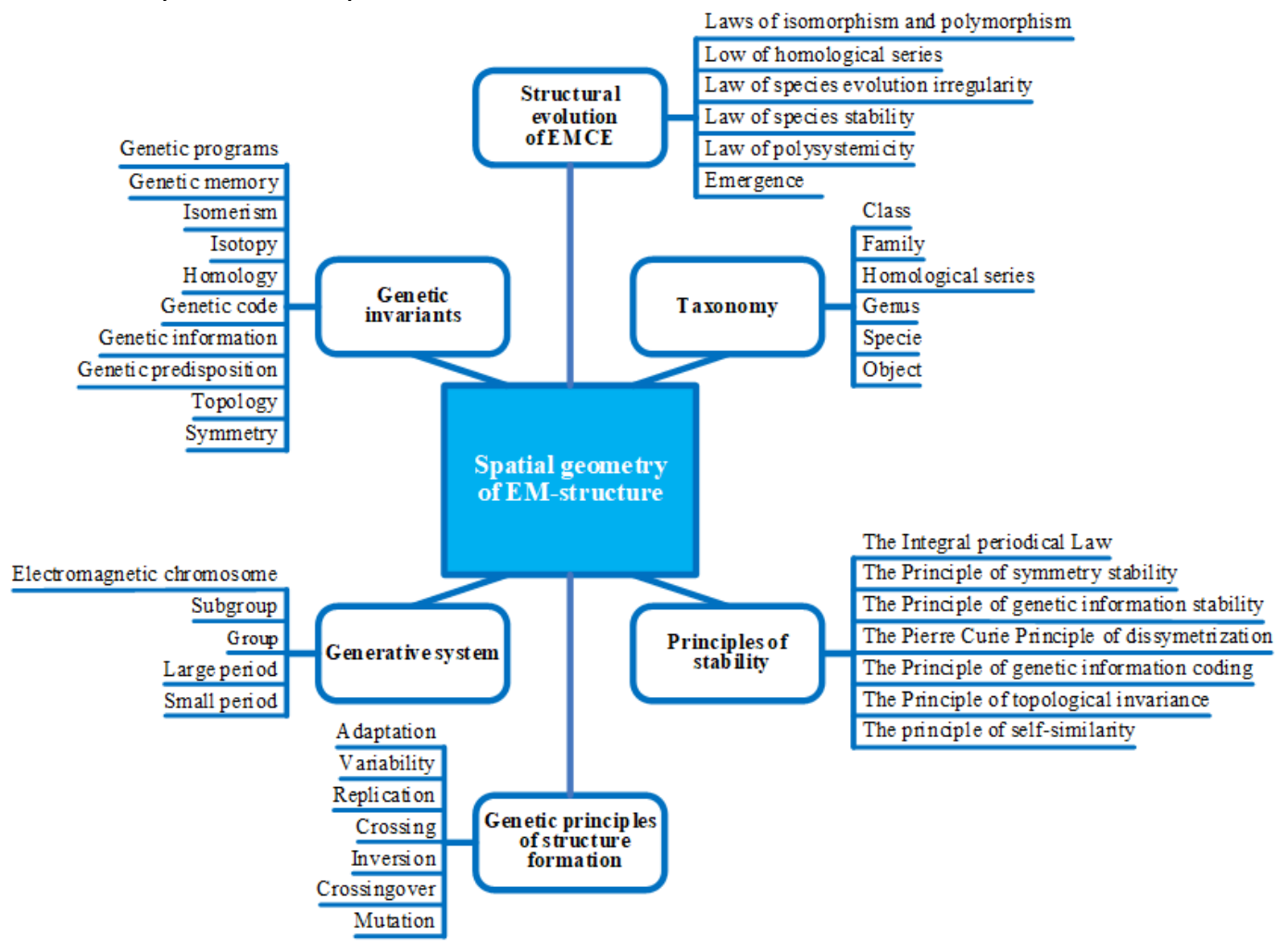

Figure 2: Ontology of the Category "Spatial Geometry of Electromagnetic Structure" in the Theory of Genetic Evolution of Electromechanical Converters of Energy 


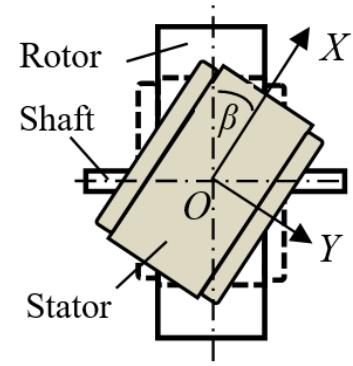

Figure 3: The Model of Electric Machine with OZ-rotary Stator

$Q_{P L}=(P L 0.0 y ;$ PLO.0x; PL0.2y; PL2.0x; PL2.2y; PL2.2x), (3)

as well as two chromosomes of the Toroidal Flat Genus

$$
Q_{T P}=(T P 2.2 y ; T P 2.2 x)
$$

Spatial OZ-rotation is also allowed by hybrid electromagnetic chromosomes of the intraspecific level:

$$
\begin{aligned}
Q_{H}= & \left\{(P L 2.2 x, y)_{1} \times(C L)_{2} ;(P L 2.2 x, y)_{1} \times(T P)_{2} ;\right. \\
& \left.(P L 2.2 x, y)_{1} \times(S F)_{2} ;(T P 2.2 x, y)_{1} \times(P L)_{2}\right\} .
\end{aligned}
$$

The finite set of electromagnetic chromosomes (2-5) is generalized by the concept of macrogenetic program of structure formation of a functional class of objects with $O Z$-rotating active parts. The macrogenetic program contains information about the genetically acceptable elemental basis, which determines the Species diversity of both known and potentially possible EMobjects with a rotary inductor of the OZ-type.

Analysis of the spatial geometry and topology of paired electromagnetic chromosomes of the first large GC period shows that asymmetric field sources of group 2.2 with $x-y$ topological invariance are endowed with the maximum genetic predisposition to change the spatial orientation. Such topological properties (provided that the value of the air gap $\delta \approx$ const is unchangeable) occur only in two primary sources of the electromagnetic field with genetic codes:

$$
P L 2.2 y=P L 2.2 x ; S F 2.2 y=S F 2.2 x,
$$

as well as at the level of their electromechanical pairs:

$$
\begin{aligned}
& (P L 2.2 y)_{1} \times(P L)_{2}=(P L 2.2 x)_{1} \times(P L)_{2} ; \\
& (S F 2.2 y)_{1} \times(S F)_{2}=(S F 2.2 x)_{1} \times(S F)_{2} .
\end{aligned}
$$

The spatial geometry of the active zone of the descendant structures which are synthesized on the basis of chromosomes (6) is not "sensitive" to changes in the orientation of the active surfaces relative to the $O Z$-normal. But the change of the orientation of the active parts significantly affects the electromagnetic, electromechanical and functional properties of EM-structures-descendants. Genetic principles of mutation and structural replication determine the principles of structural synthesis of multi-element electric machines and electromechanical devices of modular design [14], [15], [16].
The relationship between genetic codes and the tendency to relative rotation at the level of paired electromagnetic chromosomes is evidence that electromechanical structures (EMstructures) with variable active zone geometry will occur at all other levels of structural complexity of a genetically organized EM-system: chromosomal (combinatorial space of paired electromagnetic chromosomes), elemental (active sections of windings, poles, moving active elements), object (inductors, armatures, rotors) and systemic (electromechanical systems with spatially distributed and active parts, etc.) levels.

\section{Principles of Structure Formation of Objects with Adaptive Geometry of the Active Surface}

In the theory of genetic synthesis electromagnetic structures with a violation of proportions, geometric relationships, or a violation of the electromagnetic symmetry of the active parts belong to the class of genetically mutated [6]. The system-wide principle of mutation is one of the most productive and least studied mechanisms of structure formation in GOS both of natural and of anthropogenic origin. In the methodology of genetic synthesis the corresponding group of homeomorphic transformations is matched to the mutation operator $M$. The genetic operator of the mutation changes the genetic information of an arbitrary structure, generating a sequence of homologous structures within a given topological space $R^{T}$ :

$$
M(S) \rightarrow\left(S_{M 1}, S_{M 2}, \ldots, S_{M n}\right) \subset R^{T}, \overline{1, \infty}
$$

The topological equivalent of mutational transformations is volume or surface deformations of active elements or surfaces as well as changes in the spatial geometry and orientation of their relative position. The most well-known representatives of genetically mutated EM-objects are electric machines with beveled grooves, functional classes of electric motors with a rolling rotor, EM-objects with rotary stators and variable geometry of the active surface and so on. Topological model (9) indicates the unique role of mutations in understanding the mechanisms of intraspecific, interspecific and intergeneric structural relationships and transformations. Analysis of the mechanisms of mutagenesis in technical objects opens the possibility of structural prediction and synthesis of fundamentally new structural varieties.

In applied tasks of genetic synthesis, the operator $M$ is matched with a group of continuous spatial deformations, compression, tension, shear, rotation, torsion and others. In procedures for the synthesis of multi-element EM-structures the mutation operator forms a stable combination with the replication operator and isomeric compositions the structural equivalents of which are spatially distributed modular structures.

In the general case for the replication coefficient $k_{r} \geq 2$ the mutated structure $S_{M}$ allows $N$ variants of spatial isomeric compositions in $R^{3}$ the number of which will increase with increasing value of $k_{r}$

$$
M\left(S_{M}\right) \rightarrow k_{r} s \in K_{i} \subset R^{3}, i=\overline{1 \div N}
$$


where: $S_{M}$ - electromagnetic mutant chromosome; $k_{r}$ - replication rate; $R^{3}$ - three-dimensional space of existence of isomeric compositions $K_{i}$.

The basis of the structure formation of EM-structures classes which allow spatial elastic deformation of the active surface is the fundamental principle of topological invariance which determines the structure and properties of primary elements within an arbitrary subgroup of periodic GC. From the point of genetic information topologically equivalent chromosomes form the corresponding horizontal series of homologous EM-structures which are subject to the realization of elastic deformation of the active zone provided the electromagnetic structure and topology stability. In the structure of the first large period of the GC there are six such series

$$
T=\left(H_{00 y}, H_{00 x}, H_{02 y}, H_{20 x}, H_{22 y}, H_{22 x}\right) .
$$

According to the criterion of maximum adaptation to changes in the spatial geometry of the active surface of EM-objects the highest level of genetic predisposition is endowed with electromagnetic chromosomes of group 2.2. Within the first large period of GC the genetic information of the sources of group 2.2 is represented by two horizontal homologous series

$$
\begin{gathered}
T_{22 y}=(C L 2.2 y ; K N \text { 2.2y;PL 2.2y; } \\
T P 2.2 y ; S F 2.2 y ; T C 2.2 y) \\
T_{22 x}=(C L 2.2 x ; K N 2.2 x ; P L 2.2 x ; \\
T P 2.2 x ; S F 2.2 x ; T C 2.2 x)
\end{gathered}
$$

For electric machines with solid secondary parts which implement rotational or translational spatial motion the range of generating structures is limited by the chromosome set of the subgroup $T_{22 y}$. It si known that the changing in the spatial geometry of homologous electromagnetic chromosomes is related to the homeomorphism relation:

$$
\begin{aligned}
& H_{22 y}=(\ldots \leftrightarrow C L \leftrightarrow K N \leftrightarrow P L \leftrightarrow T P \leftrightarrow S F \leftrightarrow \\
&\leftrightarrow T C \leftrightarrow \ldots) 2.2 y \subset R^{3}
\end{aligned}
$$

In synthesis algorithms the homeomorphism of chromosomes (14) is realized by procedures of intergeneric chromosomal mutations which leads in changing of the Generic geometry of the corresponding chromosome within a given topological space. The genetically admissible set of intergeneric chromosomal mutations is theoretically determined by the combinatorial space of chromosomes of group 2.2 and is practically limited by their possibility of technical realization of structures-descendants. Paired chromosomal mutations $\left(N_{l}=2\right)$ will be of the greatest practical value within subgroup $2.2 \mathrm{y}$ whose genetic predisposition is sensitive both to changes in the spatial orientation of active parts and to changes in the geometry of the active surface. These chromosomal mutations have a deterministic relationship with the spatial geometry of the active surface and the type of spatial motion of objects-descendants (Table 2).

Systematized information which is presented in Table 2 can be considered as a system basis for the structure formation of objects of "elastic electromechanics" of subgroup $2.2 \mathrm{y}$ for the combinatorial space $N_{l}=2$.

The invariant component of the genetic code $(2.2 y)$ indicates a common topological space within homeomorphic transformations are allowed. Changing the geometry of an arbitrary chromosome of a series (14) is carried out using a genetic mutation operator (9). Homeomorphism of primary

\begin{tabular}{|c|c|c|c|}
\hline $\begin{array}{c}\text { Intergeneric } \\
\text { chromosomal } \\
\text { mutations }\end{array}$ & Type of spatial deformation & $\begin{array}{l}\text { Structural formula of } \\
\text { mutated chromosome }\end{array}$ & $\begin{array}{c}\text { Type of spatial motion of objects- } \\
\text { descendant }\end{array}$ \\
\hline$P L \leftrightarrow C L$ & $M_{O Y}$ & $2.2 y(P L \leftrightarrow C L)_{1}$ & Progressive $\left(V_{O X}\right) \leftrightarrow$ rotational $\left(\omega_{O Y}\right)$ \\
\hline$P L \leftrightarrow T P$ & $M_{O Z}$ & $2.2 y(P L \leftrightarrow T P)_{1}$ & Progressive $\left(V_{O X}\right) \leftrightarrow$ rotational $\left(\omega_{O Z}\right)$ \\
\hline$P L \leftrightarrow S F$ & $\left(M_{O Y} \leftrightarrow M_{O X}\right)_{R}$ & $2.2 y(P L \leftrightarrow S F)_{1}$ & Progressive $\left(V_{O X}\right) \leftrightarrow$ rotational $\left(\omega_{O Y}\right)$ \\
\hline$C L \leftrightarrow S F$ & $M_{O X}$ & $2.2 y(C L \leftrightarrow S F)_{1}$ & Rotational $\left(\omega_{O Y}\right)$ \\
\hline$P L \leftrightarrow K N$ & $M_{O Z} \leftrightarrow M_{O Y}$ & $2.2 y(P L \leftrightarrow K N)_{1}$ & Progressive $\left(V_{O X}\right) \leftrightarrow$ rotational $\left(\omega_{O Y}\right)$ \\
\hline$T P \leftrightarrow K N$ & $M_{O Y}$ & $2.2 y(T P \leftrightarrow K N)_{1}$ & Rotational $\left(\omega_{O Z}\right) \leftrightarrow\left(\omega_{O Y}\right)$ \\
\hline$C L \leftrightarrow K N$ & $M_{O Z}$ & $2.2 y(C L \leftrightarrow K N)_{1}$ & Rotational $\left(\omega_{O Y}\right)$ \\
\hline$K N \leftrightarrow S F$ & $\left(M_{O X} \leftrightarrow M_{O Y}\right)_{R}$ & $2.2 y(K N \leftrightarrow S F)_{1}$ & Rotational $\left(\omega_{O Y}\right)$ \\
\hline$T P \leftrightarrow S F$ & $\left(M_{O X} \leftrightarrow M_{O Y}\right)_{R}$ & $2.2 y(T P \leftrightarrow S F)_{1}$ & Rotational $\left(\omega_{O Z}\right) \leftrightarrow\left(\omega_{O Y}\right)$ \\
\hline$C L \leftrightarrow T P$ & $M_{O Y} \leftrightarrow M_{O Z}$ & $2.2 y(C L \leftrightarrow T P)_{1}$ & Rotational $\left(\omega_{O Y}\right) \leftrightarrow\left(\omega_{O Z}\right)$ \\
\hline$C L \leftrightarrow T C$ & $\begin{aligned} {\left[M_{O Y} \leftrightarrow\left(M_{O X}\right)_{R I} \leftrightarrow\left(M_{O Z}\right)_{R 2}\right] } & \\
& \text { where }\left(R_{2}>R_{I}\right)\end{aligned}$ & $2.2 y(C L \leftrightarrow T C)_{1}$ & Rotational $\left(\omega_{O Y}\right) \leftrightarrow\left(\omega_{O Z}\right)$ \\
\hline$P L \leftrightarrow T C$ & $\begin{array}{c}{\left[\left(M_{O X}\right)_{R 1} \leftrightarrow\left(M_{O Z}\right)_{R 2}\right]} \\
\text { where }\left(R_{2}>R_{I}\right)\end{array}$ & $2.2 y(P L \leftrightarrow T C)_{1}$ & Progressive $\left(V_{O X}\right) \leftrightarrow$ rotational $\left(\omega_{O Z}\right)$ \\
\hline$K N \leftrightarrow T C$ & $\begin{array}{c}{\left[\left(M_{O Z}\right)_{R 2} \leftrightarrow\left(M_{O X}\right)_{R I}\right]} \\
\text { where }\left(R_{2}>R_{I}\right)\end{array}$ & $2.2 y(K N \leftrightarrow T C)_{1}$ & Rotational $\left(\omega_{O Y}\right) \leftrightarrow\left(\omega_{O Z}\right)$ \\
\hline$S F \leftrightarrow T C$ & $\begin{array}{c}{\left[\left(M_{O X}\right)_{R 1} \leftrightarrow\left(M_{O Z}\right)_{R 2}\right]} \\
\text { where }\left(R_{2}>R_{I}\right)\end{array}$ & $2.2 y(S F \leftrightarrow T C)_{1}$ & Rotational $\left(\omega_{O Y}\right) \leftrightarrow\left(\omega_{O Z}\right)$ \\
\hline
\end{tabular}
sources of the electromagnetic field indicates the practical possibility of "elastic" formation at the level of electromagnetic twin structures which elemental basis is determined in the periodic structure of GC by isotope sources [17].

Table 2: Relationship between Intergeneric Chromosomal Mutations, Active Surface Geometry and the Type of Spatial Motion of EM-objects-descendant (Subgroup $\mathrm{T}_{22 \mathrm{y}}$ ) 
This pattern of interspecific topological formation is also characteristic of some biological species which was first noticed by the Scottish biologist and mathematician D'Arcy Thompson in 1917 [18]. The use of a group of topologically equivalent transformations (continuous deformations) allows the transition from the spatial geometry of the structure of one Genus to the spatial forms of other Homologous Genus. Therefore, the procedures for the synthesis of homologous EM-structures according to model (14) acquire the status of intergeneric mutations which are directly related to the change of the first component of the genetic information of the genetic code. This once again confirms the conclusion about the structural evolution of electromechanical objects occurs not only on the principle of heredity (i.e. within vertical Homologous Series) but also largely through the horizontal exchange of information within horizontal Homologous Series.

\section{Genetic Synthesis}

The homeomorphism of the primary structures of subgroups opens the possibility of the synthesis of EM-objects which are endowed with the property of changing their own spatial geometry within a genetically determined topological space. For example genetic information for a structure whose active surface can change geometry within three topologically equivalent geometric shapes $\left(N_{G}=3\right)$ for subgroup $H_{22}$ can be represented as the result of a local intergeneric mutation

$$
S_{M}=\left(H_{C L} \leftrightarrow H_{P L} \leftrightarrow H_{T P}\right) 2.2 \mathrm{y} \subset H_{22} .
$$

Formula (15) corresponds to the model of a mutated EMstructure the geometry of the active surface of which can alternately exist in one of three generic forms flat, cylindrical or toroidal flat (Figure 4).

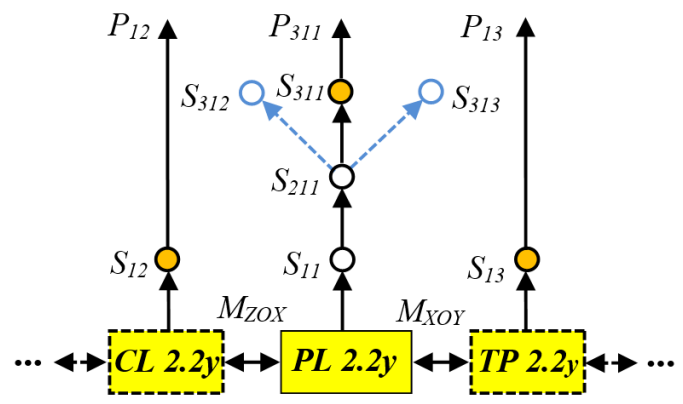

Figure 4: Genetic Model of Intergeneric Mutated EM-structure $\left(N_{G}=3\right)$ with Variable Geometry of Active Surface Synthesis
The results of the microgenetic program decoding confirm the dominant role of the mutation operator $\left(M_{i}\right)$ in the procedures of formation of EM-objects with variable geometry of the active surface (Table 3).

The results of genetic analysis of the model allow to obtain the structural formula of the integrated mutated chromosome $S_{M 3}$

$$
S_{M 3} \rightarrow\left(P L 2.2_{y}\right)_{1} \rightarrow\left\{\begin{array}{l}
M_{Z O X} \rightarrow\left(C L 2.2_{y}\right)_{1} \times\left(C L 2.2_{y}\right)_{2} \\
M_{O Z} \rightarrow\left[(P L 2.2 y): M_{X O Y}\right]_{2} \\
M_{X O Y} \rightarrow\left(T P 2.2_{y}\right)_{1} \times\left(T P 2.2_{y}\right)_{2}
\end{array}\right\}
$$

Technical implementation of the synthesized on the basis of the $S_{M}$ chromosome structure is possible if two opposite requirements are provided: providing of elastic deformation and maintaining the required mechanical stiffness of the active surface of the inductor. Modern polymers and composites allow to implement these requirements. One of the possible technical solutions involves the implementation of a hybrid design of the inductor, in which U-shaped magnetic conductors with concentrated windings, mechanically combined into a monolithic structure using a polymer-reinforced filler with a high coefficient of elasticity (Figure 5).

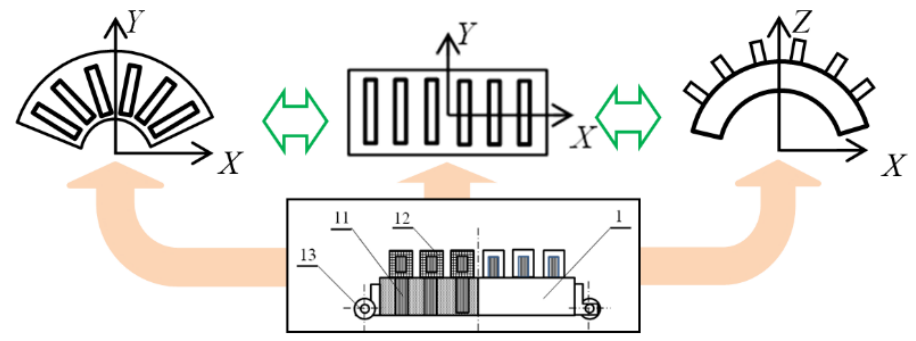

Figure 5: Multifunctional Inductor Module with Spatially Adaptive Active Surface (Chromosomal Mutation CL2.2y $\leftrightarrow P L 2.2 y \leftrightarrow T P 2.2 y$ )

Was Synthesized on the Basis of the Electromagnetic Chromosome $S_{M 3}$

Genetically synthesized inductor is endowed with a unique ability to function with the ability to sequentially change the geometry of the core (cylindrical $C L \leftrightarrow$ flat $P L \leftrightarrow$ toroidal flat $T P$ ), which opens the possibility of implementing both translational and rotational motion of the moving part. Electromechanical objects with such properties can be generalized to the concept of objects of "elastic" electromechanics.

Table 3: The Results of Decoding of the Electromagnetic Chromosomes Local Intergeneric Mutation Microgenetic Program $\left(\mathrm{N}_{\mathrm{G}}=3\right)$

\begin{tabular}{|c|c|c|c|}
\hline $\begin{array}{c}\text { Chromosomal } \\
\text { code }\end{array}$ & $\begin{array}{c}\text { Structural formula of synthesized } \\
\text { chromosome }\end{array}$ & Chromosomal status & $\begin{array}{c}\text { Weighting } \\
\text { factor }\end{array}$ \\
\hline \multirow{3}{*}{$P L 2.2 y$} & $P L 2.2 y$ & Parental & - \\
\cline { 2 - 4 } & {$\left[(P L 2.2 y): M_{Z O X}\right]_{1} \rightarrow(C L 2.2 y)_{1}$} & Parental mutated & - \\
\cline { 2 - 4 } & {$\left[(P L 2.2 y): M_{X O Y}\right]_{1} \rightarrow(T P 2.2 y)_{1}$} & Parental mutated & - \\
\hline$S_{11}$ & $(P L 2.2 y)_{1} \times(P L 2.2 y)_{2}$ & Electromagnetic double, informational & - \\
\hline$S_{I 2}$ & $(C L 2.2 y)_{1} \times(C L 2.2 y)_{2}$ & Electromagnetic double, generative & 0.3 \\
\hline$S_{13}$ & $(T P 2.2 y)_{1} \times(T P 2.2 y)_{2}$ & Electromagnetic double, generative & 0.6 \\
\hline$S_{211}$ & {$\left[(P L 2.2 y): M_{O Z}\right]_{1} \times(P L 2.2 y)_{2}$} & Mutated $(O Z$-rotative), informational & - \\
\hline$S_{311}$ & {$\left[(P L 2.2 y): M_{O Z}\right]_{1} \times\left[(P L 2.2 y): M_{X O Y}\right]_{2}$} & Mutated $\left(M_{X O Y}\right)_{2}$, generative & 0.8 \\
\hline$S_{\Sigma}$ & $\left(S_{I 2} \leftrightarrow S_{I 3} \leftrightarrow S_{311}\right)$ & Integral, generative & 1.0 \\
\hline
\end{tabular}




\section{Practical Implementation}

One of the urgent tasks is to create modern technological complexes designed for technological preparation and processing of rolled steel and large diameter steel pipes. The problem of synthesis will be considered on the example of creating a traction spatially adaptive EM-system of a robotic technological complex for processing large diameter steel pipes. The initial information for the synthesis of a genetic model is a set of requirements for the desired structure of the EM-system and the results of the analysis of its macrogenetic program.

The integral function of $F_{S}$ synthesis must satisfy the following set of partial requirements:

1) To provide the possibility of functioning with steel products of both cylindrical and flat spatial shape $\left(G_{2 C L}, G_{2 P L}\right)$ which simultaneously perform the function of the secondary part of the EM system;

2) To implement progressive, rotational and complex spatial motion of the technological object $(\omega \times V)$;

3) To minimize the number of functional modules of the EM system $\left(\mathrm{M}_{I} \rightarrow \min \right)$;

4) To provide ability of quick changing of the spatial layout and number of active inductor modules in the structure of the manipulator $\left(N_{I} \rightarrow\right.$ var $)$.

Taking into account these partial requirements, the vector of the integral synthesis function in the search space $R^{n}$ takes the form:

$$
F_{S}=\left[\left(G_{2 C L}, G_{2 P L}\right) ;(\omega \times V) ;\left(\mathrm{M}_{I} \rightarrow \min \right) ;\left(N_{I} \rightarrow v a r\right)\right] \subset R^{n} .(17
$$

Requirement 3 is provided by changing the spatial orientation of the elementary inductor module relative to the surface of the process object (OZ-rotation) and changing the spatial geometry of the active surface of the inductor module under the action of magnetic gravity whith condition to provide constantally of the air $\left(\delta_{O Z} \rightarrow\right.$ const $)$.

The multilevel genetic model of the divergent type is corresponds to given search function (17) (Figure 6).

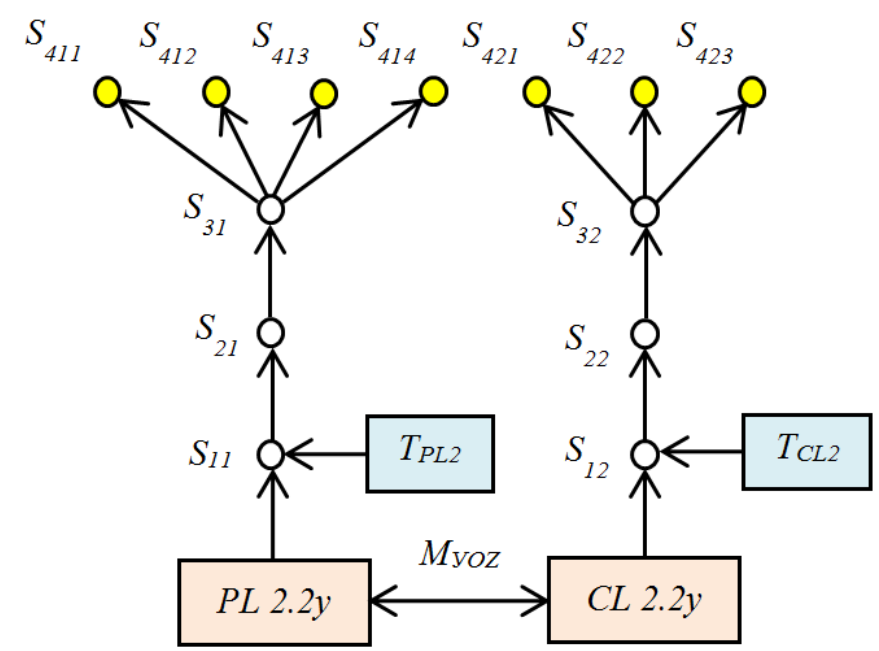

Figure 6: Genetic Model of Spatially Distributed Modular EM-system with Adaptive Geometry of Active Zone
The structure of the model contains five levels of genetic complexity which are represented by: the parent electromagnetic chromosome PL 2.2y of the dominant type of EM-structures (zero level); parallel sequences of genetically modified electromagnetic chromosomes of information type $\left(S_{11}-S_{32}\right)$ which determine the trajectory of synthesis of the desired EM-structure (levels 2-4); isomeric spatial compositions of generating electromagnetic chromosomes $\left(S_{411}-S_{414} ; S_{421}-S_{423}\right)$ which satisfy the given function of synthesis and model the spatially distributed structure of the modular EM-system (level 5).

A characteristic feature of the genetic model (Figure 6) is determined by the homeomorphism of the parent chromosomes $P L 2.2 y$ and $C L 2.2 y$ which can coexist in two geometric forms of the active surface through the operator of the intergeneric mutation $\left(\mathrm{MyOz}_{\mathrm{y}}\right)$

$$
M_{\mathrm{YOZ}}\left[2.2 y(P L \leftrightarrow C L)_{\mathrm{ZOX}}\right]_{1} \subset T_{22 Y} .
$$

Another type of mutation is represented by chromosomes $S_{21}$ and $S_{22}$ which simulate their ability to implement the relative $O Z$ rotation of the active parts. These chromosomal mutations determine the procedure of synthesis of the EM-structure which is able to alternately implement the function of a flat inductor of progressive motion or an arc cylindrical inductor of rotational motion which depends on the type of secondary chromosome which simulates the spatial geometry of the object. Variants of the spatial geometry of the active surface of the technological object (requirement 1) in the model are represented by secondary transit chromosomes $T_{P L 2}$ and $T_{C L 2}$. The results of decoding the microgenetic program are given in Table 4.

The results of the analysis of the microgenetic program (Table 4) confirm the dominant role of mutation $\left(M_{i}\right)$ and replication $\left(R_{i}\right)$ operators in the formation procedures of isomeric compositions which determine the genetic nature of the structure of modular EM-objects with variable structure and active zone geometry. The structural formulas of isomeric chromosomal compositions $S_{411}-S_{414}$ (for functioning with flat objects) and $S_{421-}$ $S_{423}$ (for functioning with cylindrical objects) which have the status of generative satisfy the given $F_{S}$ function. Each of these isomeric compositions is associated with a specific structural equivalent of the generic geometry, spatial location and orientation of the inductor modules.

Genetic synthesis procedures reproduce the deterministic relationship between genetic synthesis operators and isomeric compositions of electromagnetic chromosomes on the one hand and the pattern of inductor modules and the type of spatial motion on the other. Structural isomerism is a systemic property of genetically organized systems of arbitrary physical nature with a multi-element $(N \geq 2)$ structure, to form $N_{i}$ variants of spatial compositions. The phenomenon of isomerism of primary sources of electromagnetic fields was first discovered and described in the analysis of invariant properties of the system model - Genetic Classification of primary sources of electromagnetic fields [6]. The synthesized isomeric compositions allow to determine the spatial layout schemes of inductor modules and the corresponding types of spatial motion of the technological object depending on its type and spatial geometry (Table 4). 
Table 4: The Results of a Modular EM-system with Variable Spatial Structure and Active Zone Geometry Structure Formation Microgenetic Program Decoding

\begin{tabular}{|c|c|c|}
\hline $\begin{array}{l}\text { Chromo- } \\
\text { somal number }\end{array}$ & Structural formula of synthesized chromosome & Chromosomal status \\
\hline \multirow{2}{*}{$P L 2.2 y$} & $P L 2.2 y$ & Parental \\
\hline & {$\left[(P L 2.2 y): M_{Z O y}\right]_{1} \rightarrow(C L 2.2 y)_{1}$} & $\begin{array}{c}\text { Parental, intergeneric } \\
\text { mutant }\end{array}$ \\
\hline$S_{11}$ & $(P L 2.2 y)_{1} \times\left(T_{P L}\right)_{2}$ & $\begin{array}{c}\text { Electromagnetic double, } \\
\text { informational }\end{array}$ \\
\hline$S_{21}$ & {$[(P L 2.2 y): M]_{1} \times\left(T_{P L}\right)_{2}$} & Mutated, informational \\
\hline$S_{31}$ & {$[(P L 2.2 y): M: R]_{1} \times\left(T_{P L}\right)_{2}$} & Replicated, informative \\
\hline$S_{411}$ & {$\left[(P L 2.2 y): M: R_{X O Y}: V_{O X}\right]_{1} \times\left(T_{P L}\right)_{2}$} & $\begin{array}{c}\text { Isomer }(O X \text {-oriented }), \\
\text { generative }\end{array}$ \\
\hline$S_{412}$ & {$\left[(P L 2.2 y): M: R_{\text {Хоу }}: V_{O Y}\right]_{1} \times\left(T_{P L}\right)_{2}$} & $\begin{array}{c}\text { Isomer ( } O Y \text {-oriented), } \\
\text { generative }\end{array}$ \\
\hline$S_{412}$ & {$\left[(P L 2.2 y): M: R_{X O Y}: \omega_{O Z}\right]_{1} \times\left(T_{P L}\right)_{2}$} & $\begin{array}{c}\text { Isomer (OZ-rotative), } \\
\text { generative }\end{array}$ \\
\hline$S_{413}$ & {$\left[(P L 2.2 y): M: R_{X O Y}: V_{O X}: V_{O Y}: \omega_{O Z}\right]_{1} \times\left(T_{P L}\right)_{2}$} & Isomer $(V, \omega)_{X O Y}$, generative \\
\hline$S_{12}$ & $(C L 2.2 y)_{1} \times\left(T_{C L}\right)_{2}$ & $\begin{array}{c}\text { Electromagnetic double, } \\
\text { informational }\end{array}$ \\
\hline$S_{22}$ & {$[(C L 2.2 y): M]_{1} \times\left(T_{C L}\right)_{2}$} & Mutated, informational \\
\hline$S_{32}$ & {$[(C L 2.2 y): M: R]_{1} \times\left(T_{C L}\right)_{2}$} & Replicated, informative \\
\hline$S_{421}$ & {$\left[(P L 2.2 y): M: R_{Z O y}: V_{O X}\right]_{1} \times\left(T_{C L}\right)_{2}$} & $\begin{array}{c}\text { Isomer }(O X \text {-oriented }) \text {, } \\
\text { generative }\end{array}$ \\
\hline$S_{422}$ & {$\left[(C L 2.2 y): M: R_{\text {ZOy }}: \omega_{O X}\right]_{1} \times\left(T_{C L}\right)_{2}$} & $\begin{array}{c}\text { Isomer ( } O X \text {-rotative }), \\
\text { generative }\end{array}$ \\
\hline$S_{423}$ & $\left.\left[(P L 2.2 y): M: R_{Z O y}: V_{O X}\right) \leftrightarrow(C L 2.2 y): M: R_{Z O Y}: \omega_{O X}\right]_{1} \times\left(T_{C L}\right)_{2}$ & Isomer $(V, \omega)_{O X}$, generative \\
\hline
\end{tabular}

Technical implementation of a multifunctional EM-system with spatially distributed inductors carried out on a unified module with variable spatial geometry which is synthesized by a genetic formula

$$
S_{M 2} \rightarrow\left(P L 2.2_{y}\right)_{1} \rightarrow\left\{\begin{array}{l}
M_{O Z} \rightarrow\left[(P L 2.2 y): M_{X O Y}\right]_{2} \\
M_{Z O X} \rightarrow\left(C L 2.2_{y}\right)_{1} \times\left(C L P 2.2_{y}\right)_{2}
\end{array}\right\}
$$

Elastic deformation of the active surface of the modules is carried out under the action of electromagnetic gravity which allows to use one module to operate both steel pipes of different diameters and rolled steel sheets (Figure 7). The function of $\mathrm{OZ}$ rotation of modules relative to the surface of the object of operation provides the implementation of various types of spatial motion of the technological object (progressive, rotating, helical, plane-parallel or complex programmable motion).

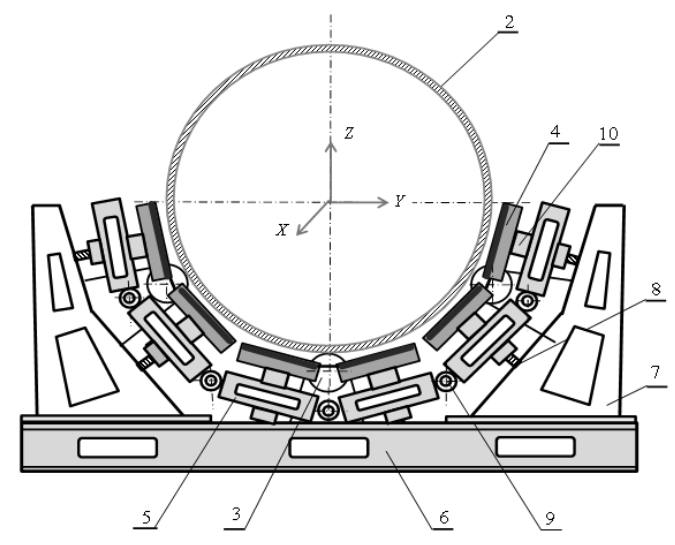

a)

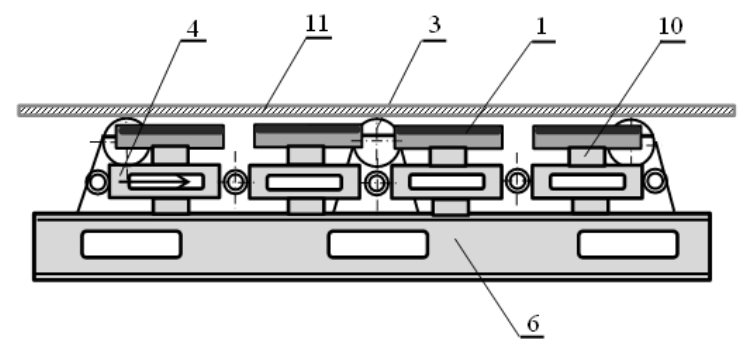

b)

Figure 7: Multifunctional Electromechanical System Based on Unified Adaptive Inductor Modules $\left(S_{M 2}\right)$ for Technological Manipulator of Steel Pipes (a) and Rolled Steel (b)

Systematized variants of spatial configurations of inductor modules (Table 5) perform the function of a genetic catalog to select the modes of operation of the spatially distributed EMsystem of the technological manipulator. The results of the analysis are also the source of information for the development of algorithms for automated process control.

The speed of the object is regulated by the changing the spatial orientation of the inductor modules using frequency or amplitudephase control. The modular structure of inductors and unification of units of the technological manipulator at the minimum expenses of time provides adaptation of spatial structure and geometry of EM-system under the given technological process. The spatial structure of the system also provides the ability to operate the number of active modules which allows to implement energy-saving algorithms for controlling the modes of operation of objects with different dimensions and weight. 
Table 5: Relationship between Genetic Information of Isomeric Compositions, the Spatial Arrangement of Active Inductor Modules and the Type of Spatial Motion of the Technological Object

\begin{tabular}{|c|c|c|}
\hline $\begin{array}{l}\text { Type of spatial } \\
\text { motion }\end{array}$ & Structural formula of isomeric compositions & $\begin{array}{l}\text { Geometry and spatial } \\
\text { arrangement of inductor } \\
\text { modules* }\end{array}$ \\
\hline \multicolumn{3}{|c|}{ The technological object is a steel pipe } \\
\hline $\begin{array}{l}\text { Progressive: } \\
\quad \pm\left(V_{O X}\right)\end{array}$ & $4(P L 2.2 x)_{X O Y}$ & $\Delta Z$ \\
\hline $\begin{array}{l}\text { Rotative: } \\
\pm\left(\omega_{O X}\right)\end{array}$ & $4\left[(C L 2.2 y): M_{O Z}(\pi / 4): M_{Z O Y}\right]_{Z O Y}$ & \\
\hline $\begin{array}{c}\text { Rotative- } \\
\text { progressive } \\
\text { (helical): } \\
\pm\left(V_{O X} \times \omega_{O X}\right) ;\end{array}$ & $2(P L 2.2 x)_{X O Y} \times 2\left[(C L 2.2 y): M_{O Z}(\pi / 4)\right]_{Z O Y}$ & \\
\hline \multicolumn{3}{|c|}{ The technological object is a steel sheet } \\
\hline $\begin{array}{l}\text { Progressive: } \\
\quad \pm\left(V_{O X}\right)\end{array}$ & $4(P L 2.2 x)_{O X}$ & 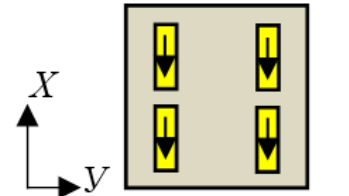 \\
\hline $\begin{array}{l}\text { Progressive: } \\
\quad \pm\left(V_{O Y}\right)\end{array}$ & $4\left[(P L 2.2 y): M_{O Z}(\pi / 4)\right]_{O Y}$ & 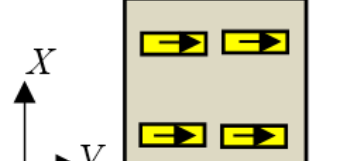 \\
\hline $\begin{array}{l}\text { Flat-parallel: } \\
\pm\left(V_{O X} \times V_{O Y}\right)\end{array}$ & $2(P L 2.2 x)_{O X} \times 2\left[(P L 2.2 y): M_{O Z}(\pi / 4)\right]_{O Y}$ & 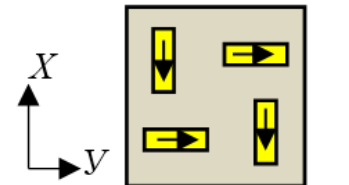 \\
\hline $\begin{array}{l}\text { Rotative: } \\
\pm\left(\omega_{o z}\right)\end{array}$ & $(P L 2.2 y): M_{O Z}[(-\pi / 4) \times(\pi / 4) \times(3 \pi / 4) \times(5 \pi / 4)]_{X O Y}$ & $\hat{\mathbf{A}}$ \\
\hline
\end{tabular}

\section{Genetic Evolution}

The results of genetic programs decoding were verified by carrying out of evolutionary experiments. The main task of the evolutionary experiment is to determine the deterministic correspondence between the genetic information of the elemental basis of genetic programs and the genetic codes of the real diversity of EM-objects-descendants that have historically emerged in the process of technical evolution [19].

The first structural representatives of objects with a change in the orientation of the active parts were induction electric machines with a rotating stator. The term "rotary stator" became known in the technical literature in the late eighteenth century after the publication of the French engineer P. Boucher [20]. But the concept of "rotary stator" turned out to be broader and ambiguous as its structural identification is associated with the specification of the spatial orientation of the axis of rotation relative to the axis of rotation or direction of movement of the moving part which in general case could be unconformitive. According to this feature electrical machines and electromechanical devices with the function of the relative orientation of their active parts can be divided into two subclasses:

- EMCE with the possibility of rotation of the active parts relative to the axis of rotation ( $O Y$-rotation);

- EMCE with the possibility of rotation of the active parts relative to normal (OZ-rotation).

In electromechanical objects the normal vector is perpendicular to the active surface of the converter. The rotation of the stator relative to the axis $O Z$ allowed to implement one of the ways of non-contact speed control of the induction motor with the possibility of reversing. Such engines were patented in the late 40 's of last century (Figure 8) [21], [22]. 


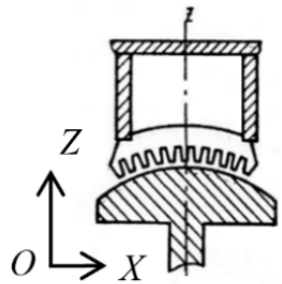

a)

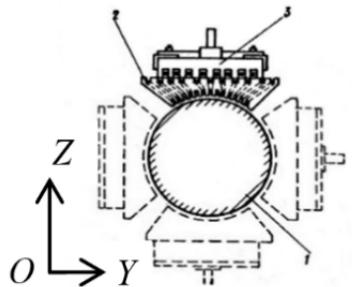

b)
Figure 8: The First Electric Machines with Rotary OZ-symmetry: a) Asynchronous Motor of the Spherical Genus (SF 2.2y); b) Induction Electric Machine of the Cylindrical Genus with a Hybrid Design of Rotary Stators (4PL 2.2y).

The historical stage of the genetic evolution of EMCE with variable spatial geometry of active parts is represented by a wide variety of electrical machines and electromechanical devices for different functional purposes. In 1966-1969 the first traction linear asynchronous motors (LAM) with a capacity of 5, 10 and $40 \mathrm{~kW}$ for driving experimental and full-scale cars of passenger overpass electric vehicles were designed, created and tested at the Special Design Bureau of Linear Electric Motors in Kyiv [23]. One of the projects involved the development of a motor with a could change the geometry of a flat active surface into a curved (arc) which significantly reduced the turning radii. In fact it was the first structural representative of traction linear motors in the design of which the principle of spatial deformation of the active surface of a moving inductor is implemented which is matched by an intergeneric mutation

$$
M_{2}\left(S_{M}\right) \rightarrow 2[(P L 2.2 y) \leftrightarrow(C L 2.2 y)]_{1} \subset H_{22} .
$$

For dynamic tests of full-scale traction linear asynchronous motors a ring-type stand with an active part of $9.74 \mathrm{~m}$ diameter was put into operation at the Special Design Bureau of Linear Electric Motors (Kyiv). The design of the stand was implemented according to the formula of an intraspecific hybrid $(P L 2.2 x)_{1} \times(T P 0.2 y)_{2}$. Dynamic tests of traction induction motors were carried out on the stand with the possibility of changing both the parameters of the secondary part and changing the geometry and power of their inductors (Figure 9, a). The development of space technology and autonomous robotic complexes have had significant affect on the intensity of research and development of spatially adaptive multi-coordinate electromechanical systems based on spherical electric machines (Figure 9, c) [24], [25], [26].

The current stage in the evolution of modular objects of spatially adaptive electromechanics is characterized by the use of new polymer and composite electromagnetic materials, printing technologies for magnetic circuits and windings as well as the capabilities of additive technologies of 3D- and 4D-printing. These technologies and the widespread use of magnetoelectric excitation systems have stimulated the development of technical solutions related to the implementation of the modular principle at all levels of the EM-object organization (Figure 10).

Thus the development of electromechanics is in accordance with the systemic laws of genetic evolution. The species diversity of EM-objects which determines the structural potential of a certain functional class is gradually expanding which is clearly illustrated by the dynamics of macroevolution of EM-objects with adaptive spatial geometry (Figure 11). The trajectory of macroevolutionary events reproduces the relationship of the elemental basis of Genetic Classification (Generative System) with real historical events of the appearance of structural representatives with the corresponding genetic codes which confirms the validity of the theory and practice of genetic evolution.

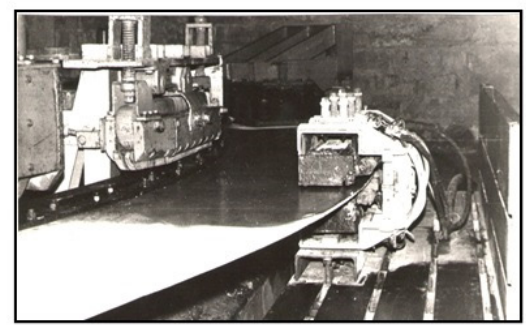

a)

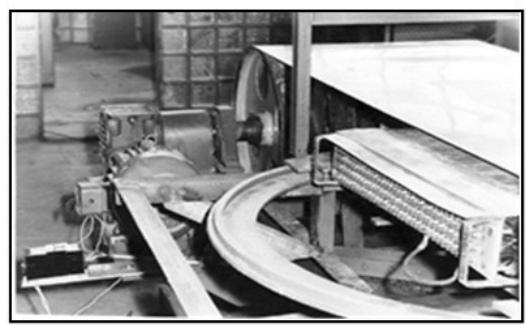

b)

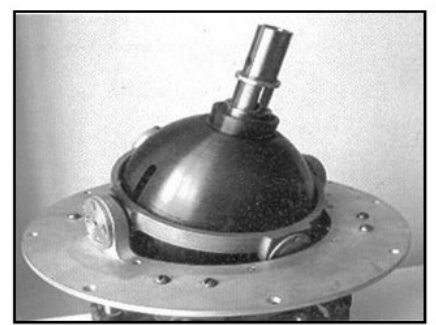

c)

Figure 9: Examples of EM-objects with Variable Spatial Orientation and Geometry of Active Parts: a) Universal Stand (Diameter $9.74 \mathrm{~m})$ for Dynamic Tests with the Possibility of Changing the Geometry of Traction Linear Induction Motors; b) Electrodynamic Separator with Flat OZ-rotary Inductor (Specie PL 2.2y) [22]; c) Threecoordinate Synchronous Motor with a Rotary Stator for Orientation Systems (Representative of the Spherical Genus) [26].
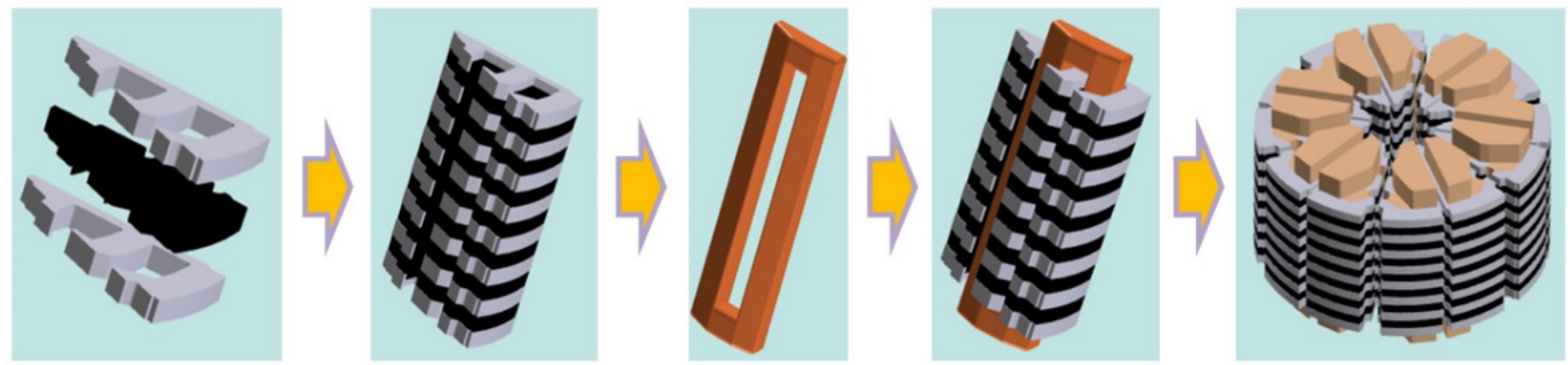

Figure 10: Multilevel Implementation of the Modular Principle in the Genetic Design of Linear Electric Motors with Transverse Magnetic Flux (Representative of the Specie CL 2.0x) by the Technology of KEEP'MOTION Company 


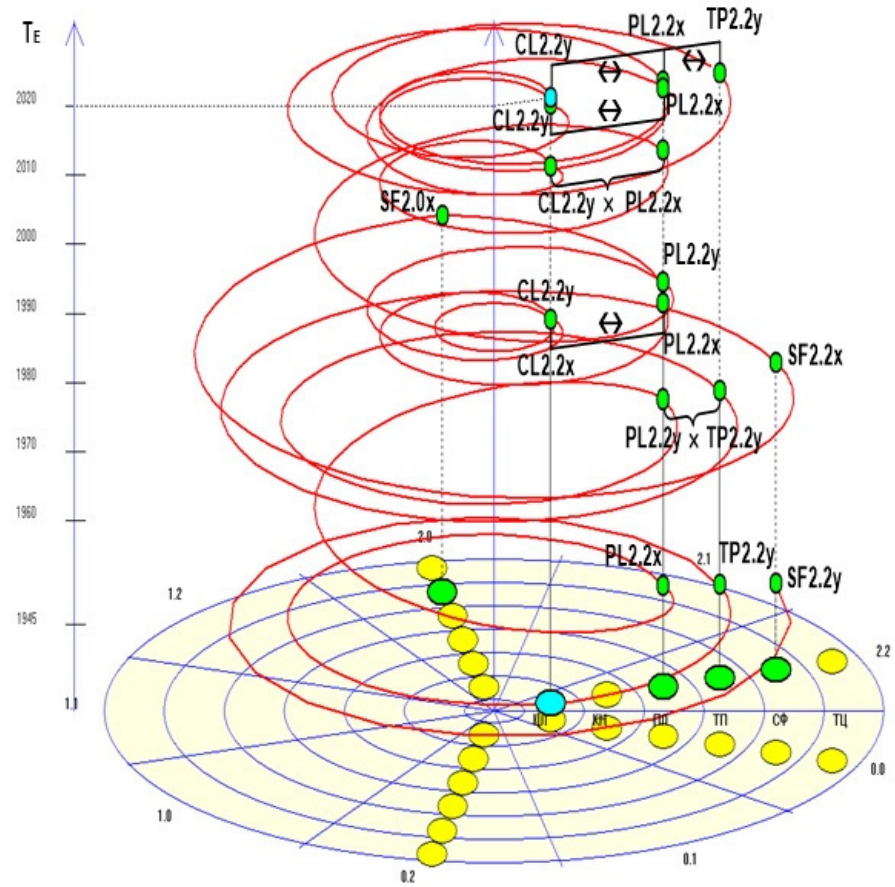

Figure 11: Macrogenetic Evolution of Species Diversity of Electric Machines with Adaptive Spatial Geometry of the Active Zone ( $T_{E}=75$ years)

The current stage of functional evolution of spatially adapted modular EM-systems is represented by a wide variety of EMobjects for different purposes (Figure 12). Modern EM-systems combine the functions of executive bodies with elements of spatial self-organization and artificial intelligence. Examples of such systems are robotic complexes with reconfigured structures [27], spatially distributed electromechanical systems of cableless passenger elevators of the MULTI series, implemented by MAGLEV technology [28], electromechanical systems of branched 3D networks-conveyors, grips and manipulators of anthropomorphic robotic systems, machining centers [5] and others. A promising area of practical use of EM-objects of elastic electromechanics are inductor systems of magnetic therapy equipment and implanted artificial life support systems in medicine [29].

The results of genetic analysis of the directions of functional evolution confirm the reliability of genetic programs and form the basis for the tasks of structural prediction and innovative synthesis of their new structural varieties. The technical evolution of spatially adaptive electromechanics in the nearest future will be largely determined by advances in materials science, genetic electromechanics, additive technologies and artificial intelligence.

\section{The New Philosophy of Synthesis}

The presence of the Generative Periodic System of primary sources of the electromagnetic field and the methodology of deciphering the structural information potential of genetic programs open the possibility of transition to the fundamentally new philosophy of creating complex technical systems with the ability to predict and discover new types and functional classes of EMCE. Such tasks are directly related to the theory of genetic Specie formation of EM-systems and the formulation of the corresponding prognostic-evolutionary experiment. The concept of Species is fundamental in the evolution of GOS as only through the category of Species it became possible to explain the mechanisms of micro- and macroevolution of EM-systems, determine genetic programs of structure formation and develop principles of genetic taxonomy of EMCE.

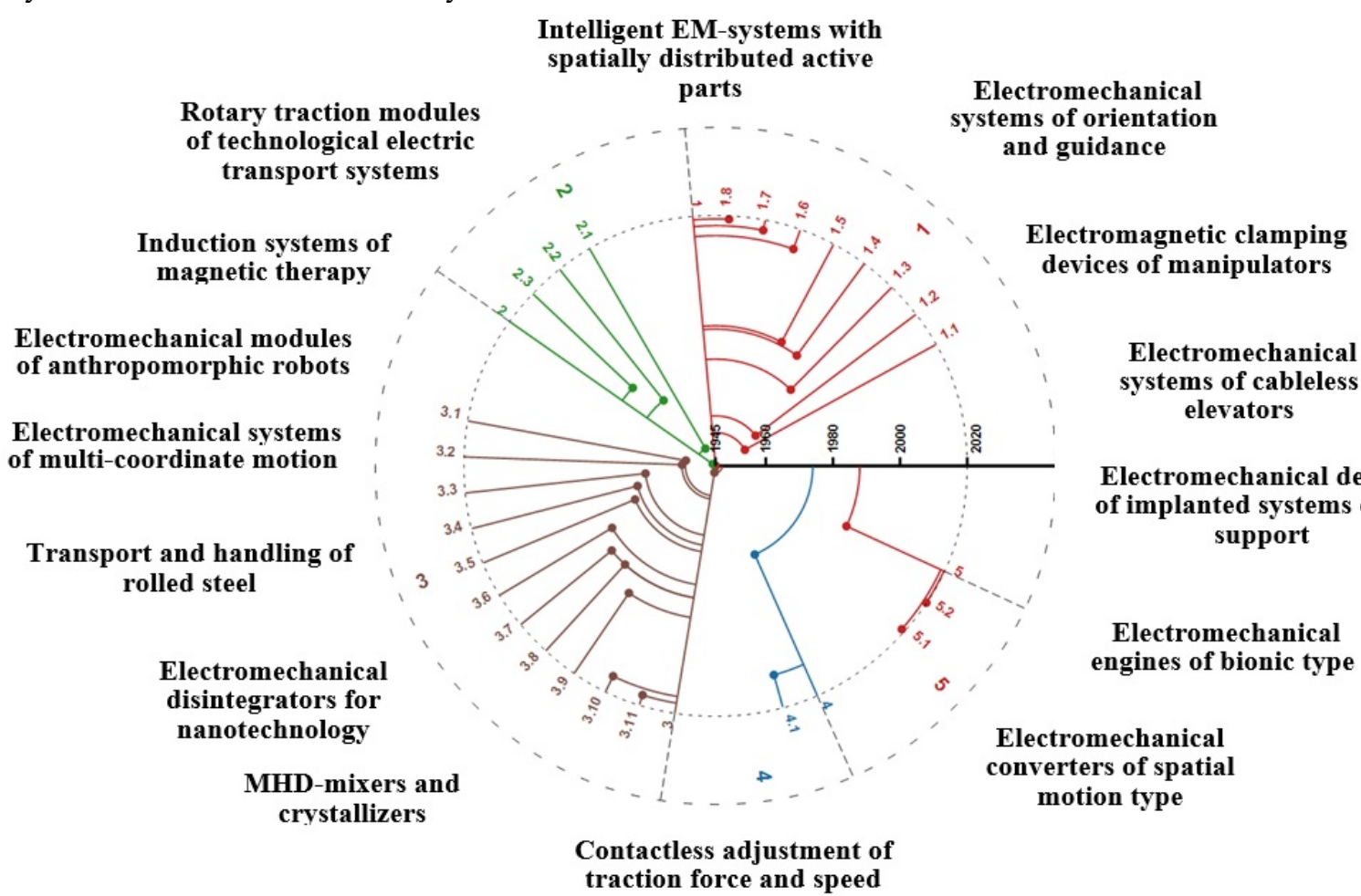

Figure 12: The Main Directions of Functional Evolution of EMCE with Variable Structure and Spatial Geometry of Active Parts 
Until recently the discovery of new Species was considered the prerogative of biological science the systemic foundation of which is biological taxonomy. The discovery of the Biological Species is a landmark scientific event of international level. In the concept of GOS the concept of Species is a natural and necessary component in the hierarchy of interrelated levels of genetic complexity of electromagnetic systems: "Electromagnetic gene" $\rightarrow$ "Electromagnetic chromosome" $\rightarrow$ "Electromagnetic structure" $\rightarrow$ "Population of structures" $\rightarrow$ "Species" $\rightarrow$ "Genus" $\rightarrow$ "Functional class of EM-objects". But the establishment of the relationship and logical sequence of these categories became possible only after the discovery of the Periodic Table of primary sources of the electromagnetic field in 1991 (Figure 1) [6].

The reliability of the theory of genetic Specie formation is confirmed by evolutionary experiments the results of deciphering dozens of macrogenetic programs [30] and the creation of technology for genetic prediction of new types of EM-objects [31].

The genetic concept of Specie formation establishes a deterministic relationship between the information of the elemental basis of GC and the Species diversity of EM-objects, between the processes of macro- and microevolution of electromechanical objects and between the history of electromechanics and its future.

Opposite to the problem of biological Species which has been remainding controversial since Darwin due to the lack of their generating system the diversity of electromagnetic Species is strictly regulated by the periodic structure of genetic classification where information on both species involved in technical evolution and currently absent stored in the form of appropriate genetic codes. This sets a precedent for setting fundamentally new intellectual tasks - the prediction, discovery and introduction into technical evolution of new Species of EMCE.

The task of new Species discovering is directly related to the synthesis and technical implementation of their first structural representatives. As an example, consider the problem of finding EM-objects with the maximum use of active volume $\left(V_{A}\right)$ of an electric machine or electromechanical device. According to the results of the analysis of electromagnetic symmetry and topology of electromagnetic chromosomes of the first large period of GC (Figure 1) it is established that only electromagnetically symmetric chromosomes of group 0.0 are endowed with the maximum genetic predisposition to the criterion $\left(V_{A} \rightarrow \max \right)$. The geometry and topology of the active surfaces of the zero group is limited by the elemental basis of two topologically equivalent subgroups ( $y$ - and $x$-orientation) with Betty number $\beta(S)=2$. At the level of multiphase windings such topology and symmetry can be provided only by magnetic systems with ring-distributed windings and the internal location of the active zone.

The reliability of the results of genetic prediction is confirmed by the results of group synthesis of representatives of a new structural class of electromechanical disintegrators (EMD) which designed for direct implementation of nanotechnologies (fine and ultrafine grinding, intensive mixing, preparation of homogeneous powder mixtures and compositions, enrichment technologies, etc.). Implementation of contradictory requirements $\left(V_{A}=100 \%\right)$ while providing technical access to the internal working chamber during operation, was ensured by implementing the modular principle with variable spatial geometry of the external electromagnetic system of EMD (Table 6).

The development of technical solutions for EMD and their subsequent group patenting simultaneously proved the discovery and introduction into technical evolution of 6 new Species of EMCE which structural representatives were absent in the history of structural electromechanics. It should be noted that in the real evolution of technology the introduction into the evolution a new Specie occurs once every $30-40$ years.

Actually, genetic electromechanics has accumulated experience in solving a number of unique problems which formulation were impossible a few years ago. It becomes obvious that the new understanding of synthesis is based on a rethinking and widespread use of systemic principles of structural and informational heredity. In each system it is possible to allocate as a building brick the elementary structures underlying technology of genetic synthesis. It is an atom in nanotechnology, a gene in biotechnology, a bit in information technology, a neuron in cognitive technology. Such system of interconnected initial structures is invariant to the time of evolution, the level of complexity of objects-descendants and their functional purpose. The transition to genetic technologies is a natural way to unity and harmony with nature, discovery and rational use of the hidden structural potential of genetic programs, creation of multifunctional integrated systems of natural-anthropogenic type, synthesized by genetic codes and models of living nature.

Table 6: Synthesized Structures of New Species of Electromechanical Disintegrators with Variable Geometry of Electromagnetic System and with 100\% Using of the Active Volume for Direct Implementation of Nanotechnologies

\begin{tabular}{|c|c|c|c|c|c|c|}
\hline $\begin{array}{c}\text { Genus } \\
\text { geometry }\end{array}$ & Cylindrical & Conical & Flat type & Toroidal flat & Spherical & $\begin{array}{c}\text { Toroidal } \\
\text { cylindrical }\end{array}$ \\
\hline Genetic code & $C L 0.0 x$ & $K N 0.0 x$ & $P L 0.0 x$ & $T P 0.0 x$ & $S F 0.0 x$ & $T C 0.0 x$ \\
\hline $\begin{array}{c}\text { Electromagnetic } \\
\text { chromosome }\end{array}$ & & & & & \\
\hline $\begin{array}{c}\text { 3D-model of } \\
\text { EMD structure }\end{array}$
\end{tabular}




\section{Conclusions}

The main results of the research can be summarized as follows:

- for the first time it is established that the principles of genetic structure formation of spatially distributed modular EM-systems with adaptive geometry of active zone are determined by electromagnetic symmetry and topological properties of generative sources of the electromagnetic field;

- for the first time macrogenetic programs of genetically admissible basic Species of EM-structures with variable orientation of active parts (18 Species) and objects of «elastic» electromechanics (12 Subspecies) which allow changing of spatial geometry of active surface are defined;

- it is established that in the algorithms of spatially adaptive systems synthesis the dominant role belongs to the operators of replication (modularity) and mutation ("elasticity") which determine the structure of modularity and "elasticity" of the synthesized structures;

- for the first time genetic programs are defined and algorithms of intergeneric mutation are developed, which determine the principles of structure formation of "elastic" electromechanics modular objects, which functioning is carried out with variable geometry of the active surface;

- the presence of a deterministic relationship between the elemental basis of the Periodic system of primary sources of the electromagnetic field (genetic program), isomeric chromosomal compositions, the spatial arrangement of active inductor modules and the type of spatial motion of the technological object is established;

- the reliability of genetic models, programs and synthesized structures is confirmed by the results of evolutionary experiments;

- practical implementation of research results is carried out on the example of project development of a competitive modular EM-system with adaptive spatial structure which is the part of a robotic technological complex designed for processing steel pipes and rolled products.

The results of research form the basis for the problems solving of innovative synthesis of new structural varieties of modular EMsystems with adaptive spatial structure of active elements and using of "elastic" electromechanics innovative technology.

\section{Conflict of Interest}

The authors declare no conflict of interest.

\section{References}

[1] A.N. Knaian, K.C. Cheung, M.B. Lobovsky, A.J. Oines, P. Schmidt-Neilsen, N.A. Gershenfeld, "The Milli-Motein: A self-folding chain of programmable matter with a one centimeter module pitch," in 2012 IEEE/RSJ International Conference on Intelligent Robots and Systems, 1447-1453, 2012, doi:10.1109/IROS.2012.6385904.

[2] I.-C. Cheng, S. Wagner, Overview of Flexible Electronics Technology, Springer, Boston, MA: 1-28, 2009, doi:10.1007/978-0-387-74363-9 1.

[3] E. Tsihosh, Supersonic aircrafts. Reference manual. Translation from Polish, Mir, Moscow, 1983

[4] V. Shikhirin, "Elastic machines and mechanisms of the future," The Summary of Technologies, 2(6), 37-42, 2001

[5] Y.N. Kuznetsov, G.J.A. Hamuyela, T.O. Hamuyela, Morphological synthesis tools and mechanisms: Monograph, Ltd "Gnosis," Kiev, 2012.

[6] V.F. Shynkarenko, Fundamentals of the Theory of Evolution of Electromechanical Systems, Naukova Dumka, Kyiv, 2002.
[7] V. Shynkarenko, V. Kotliarova, A.N. Al-Husban, "Genetical Modeling, and Experimental Analysis of the Functional Evolution of Electromechanical Energy Converters," Journal of the Technical University of Gabrovo, 49, 1520, 2015.

[8] M. Zagirnyak, V. Prus, V. Shynkarenko, "The assessment of the processes of aging of the electric machines with structural unit defects using the genetic approach," Przegląd Elektrotechniczny, 95(1), 145-148, 2019, doi:10.15199/48.2019.01.37.

[9] S.G. Inge-Vechtomov, "The search for a periodic system... in evolution," Science First Hand, 2(3), 20-25, 2004.

[10] V.F. Shynkarenko, "Isomorphisms of generative systems (on the example of electromagnetic and numeric)," Electromechanical and Energy Saving Systems, 1(45), 46-55, 2019, doi:10.30929/2072-2052.2019.1.45.46-55.

[11] R. Thom, Structural stability and morphogenesis, Logos, Moscow, 2002.

[12] A. Lima-de-Faria, Evolution without Selection: Form and Function by Autoevolution, Mir, Moscow, 1991.

[13] V. Shynkarenko, Iu. Gaidaienko, A.N. Al-Husban, "Decoding and functional analysis of genetic programs of hybrid electromechanical structures," Modern Applied Science, 8(2), 36-48, 2014, doi:10.5539/mas.v8n2p36.

[14] V. Shynkarenko, A. Makki, V. Kotliarova, A. Shymanska, "Modular Principle in the Structural organization and Evolution of Electromechanical Objects," in 2019 IEEE International Conference on Modern Electrical and Energy Systems (MEES), 162-165, 2019, doi:10.1109/MEES.2019.8896446.

[15] V. Shynkarenko, A. Makki, A. Shymanska, V. Kotliarova, "Genetic Synthesis of Electromechanical Objects of the Modular Type," in 2019 IEEE International Conference on Modern Electrical and Energy Systems (MEES), 166-169, 2019, doi:10.1109/MEES.2019.8896596.

[16] V. Shynkarenko, V. Kotliarova, P. Krasovskyi, N. Misan, "Principles of structural construction of spatially adaptive electromechanical systems with variable structure and geometry of the active surface," Bulletin of NTU "KhPI", Series: "Electric Machines and Electromechanical Energy Conversion," 3(1357), 62-70, 2020, doi:10.20998/2409-9295.2020.3.11. (In Ukrainian)

[17] V. Shynkarenko, V. Kotliarova, "Twin-objects and double-objects in the structural evolution of electromechanical energy converters," in 2017 International Conference on Modern Electrical and Energy Systems (MEES), IEEE: 116-119, 2017, doi:10.1109/MEES.2017.8248865.

[18] N. Witkovski, The Sentimental History of Science. Translation from French, CoLibri, Moscow, 2007.

[19] V.F. Shinkarenko, I.A. Shvedchikova, V.V. Kotlyarova, "Evolutionary Experiments in Genetic Electromechanics," in Proc. 13th Anniversary International scientific Conference "Unitech'13," 289-294, 2013.

[20] K.I. Shenfer, Asynchronous machines, Gosizdat, Moskow-Leningrad, 1929.

[21] P.A. Fridkin, "A new type of arc stator for an electric drive with low and adjustable rotation speeds," Electricity, 1-2, 22-23, 1945.

[22] O.N. Veselovsky, M.N. Godkin, Induction motors with open magnetic circuit, Informelectro, Moskow, 1974.

[23] V.F. Shynkarenko, "Developments of Special Design Bureau of Linear Electric Motors and their place in evolution of new types of electric transport," Collection of Scientific Works "Research on the History of Technology," 3, 8-31, 2003.

[24] D. Martínez Muñoz, Spherical machines: a literature review, 2005.

[25] O. Saßnick, Application of the Spherical Induction Motor to Dynamically Stable Robots. Marshall Plan Scholarship Research Report, 2015.

[26] A.E. Antonov, Electric machines of magnetoelectric type. Fundamentals of the theory and synthesis, IED NASU, Kiev, 2011.

[27] I.M. Makarov, V.M. Lokhin, S.V. Manko, M.P. Romanov, M.V. Kadochnikov, "Knowledge processing technologies in control problems of autonomous mechatronic-modular reconfigurable robots," Information Technologies, 8, 2-29, 2010.

[28] J. Condliffe, World's First Cable-Free Elevator Zooms Horizontally and Vertically Using Maglev Tech, MIT Technology Review, 2017.

[29] N.I. Kulikov, A.D. Kupriyanov, "Implantable auxiliary blood circulation system based on a controlled valve motor integrated with a diaphragm-type blood pump," Biotekhnosfera, 4(16), 9-14, 2011.

[30] A.A. Avgustynovych, Theoretical bases of electric machines Species genetic systematics creation, PhD Thesis, IED NASU, 2008. (In Ukrainian)

[31] V.F. Shinkarenko, "Genetic Foresight as System Basis is in Strategy of Management Innovative Development Technical Systems," Proceedings of the Tavria State Agrotechnological University, 4(11), 3-9, 2011. 